ONCOLOGY; ORAL SURGERY

\section{The status of the deep surgical margins in tongue and floor of mouth squamous cell carcinoma and risk of local recurrence; an analysis of 68 patients}

Weijers M, Snow GB et al. Int J Oral Maxillofac Surg 2004; 33: 143-149

A margin of $0.5 \mathrm{~cm}$ was as effective as greater margins in limiting local recurrence.

After resection of squamous cell carcinoma (SCC), positive surgical margins lead to a high risk of local recurrence and reduced survival. Over a $10 \mathrm{yr}$ period, 176 patients with were treated in a Dutch hospital for SCC of the tongue and floor of mouth. Those with epithelial dysplasia in margins, or SCC, and others receiving radiotherapy or surgery within 5 yrs were excluded, leaving 68 with margins free of tumour, who were then followed 5 yrs.

In 30 patients with margins $>0.5 \mathrm{~cm}, 2$ SCCs recurred, and in 38 with smaller margins, 3 recurred (NS). The authors state that because of shrinkage during histopathological specimen preparation, $0.5 \mathrm{~cm}$ equates to a surgical margin of about $0.8-1.0 \mathrm{~cm}$. There was no relationship between local recurrence and the pattern of invasion or the presence of perineural spread.

\section{doi:10.1038/sj.bdj.4811345}

PREVENTIVE DENTISTRY; CARDIOLOGY

\section{Dental caries experience in children with congenital heart disease: a case-control study}

Stecksén-Blicks C, Rydberg A et al. Int J Paediatr Dent 2004; 14: 94-100

Despite preventive dentistry programmes, children with heart disease had poorer dental health.

Nearly $1 \%$ of children are born with heart problems, and management may lead to dental risks. Vomiting, night feeding, sucrose in medication and diuretics causing xerostomia may all contribute to caries. This study involved 95\% of children born with specified complex heart disease, but no other serious medical problems, in one Swedish county over a $10 \mathrm{yr}$ period. Matched healthy controls were selected from the population register, with 41 subjects in each group. Mean ages were 6.9 yrs (cardiac) and 6.5 yrs (controls).

Mean dmfs was 5.2 in the cardiac group and 2.1 in the controls $(P<0.05)$. Differences in DMFS (0.9 and 0.3) were NS. In the 2 groups, 16 and 22 children had caries-free primary teeth. In the cardiac group, 9 molars had been extracted. Children in the cardiac group had received a mean of 3.8 fluoride varnish applications, compared with 1.8 for controls. There were significant associations between $\mathrm{dmfs}$ and fluoride varnish, prophylaxis polishes, fluoride tablets and digoxin medication (containing sucrose). The authors conclude that better preventive efforts might reduce the dental problems of children with cardiac problems.

\section{IMPLANT DENTISTRY}

\section{Association between periodontal and peri-implant conditions: a 10-year prospective study}

Karoussis IK, Müller S etal. Clin Oral Impl Res 2004; 15: 1-7

There was a relationship between periodontal and periimplant diseases which might be partly owing to common causal factors.

Implants and teeth are supported by different anatomical tissues, but increased rates of implant failure have been reported in patients with a history of periodontitis. In this study, periodontal and peri-implant conditions were compared in 127 patients (89 remained at the $10 \mathrm{yr}$ evaluation; mean age at start $49 \mathrm{yrs}$ ) who had been treated for periodontal diseases and subsequently received implants.

During the 10 yrs, 87 of a total 1,770 teeth were extracted, but no statement was made about implant loss. At the 1 and $10 \mathrm{yr}$ examinations, 179 implants were compared with selected control teeth. There were no differences in plaque and recession scores, but inflammation, probing depth and bone levels were better for control teeth than implants. When 1 to $10 \mathrm{yr}$ changes were compared for these teeth and implants, there were no significant differences at the $0.1 \%$ level. Multiple linear regression indicated that loss of support was similar for teeth and implants.

\section{doi:10.1038/sj.bdj.4811347}

\section{DENTAL RADIOLOGY; OBSTETRICS}

Antepartum dental radiography and infant low birth weight

Hujoel PP, Bollen A-M etal. JAMA 2004; 291:1987-1993

Women who received $>0.4 \mathrm{mGy}$ of dental X-ray exposure during pregnancy were more than twice as likely to have a low birth-weight (LBW) child.

Ionizing radiation in pregnancy may increase the risk of LBW babies $(<2.5 \mathrm{Kg})$; this might occur through effects on the hypothalamus-pituitary-thyroid axis (HPTA) of the mother. Dental radiographs give measurable doses to the HTPA but not the reproductive organs or foetus.

Starting from a US dental insurance database, 29,215 patients who had given birth over an 8 year period were identified, and 1,117 LBW cases identified from the birth registrations. Four control normal birth-weight cases were randomly selected for each. Care was taken to adjust for confounders.

An estimated thyroid dose of $>0.4 \mathrm{mGy}$ increased the adjusted OR for LBW by $2.27(P<0.05)$; for 0.1-0.4 mGy, it was 1.2 (NS). Respective full-term LBW adjusted ORs were 3.61 and 1.66 (both $P$ $<0.05)$. The authors comment on the very low radiation doses which may have produced these effects. Likely thyroid doses from 14 intra-oral radiographs are over $1.0 \mathrm{mGy}$.

doi:10.1038/sj.bdj.4811348 